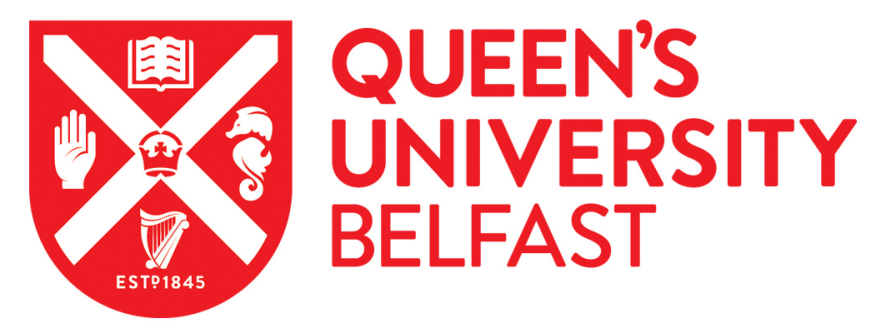

\title{
The impact of thermal mass on building energy consumption
}

Reilly, A., \& Kinnane, O. (2017). The impact of thermal mass on building energy consumption. Applied Energy, 198, 108-121. https://doi.org/10.1016/j.apenergy.2017.04.024

\author{
Published in: \\ Applied Energy
}

Document Version:

Peer reviewed version

Queen's University Belfast - Research Portal:

Link to publication record in Queen's University Belfast Research Portal

\section{Publisher rights}

Copyright 2017 Elsevier.

This manuscript is distributed under a Creative Commons Attribution-NonCommercial-NoDerivs License

(https://creativecommons.org/licenses/by-nc-nd/4.0/), which permits distribution and reproduction for non-commercial purposes, provided the author and source are cited.

\section{General rights}

Copyright for the publications made accessible via the Queen's University Belfast Research Portal is retained by the author(s) and / or other copyright owners and it is a condition of accessing these publications that users recognise and abide by the legal requirements associated with these rights.

Take down policy

The Research Portal is Queen's institutional repository that provides access to Queen's research output. Every effort has been made to ensure that content in the Research Portal does not infringe any person's rights, or applicable UK laws. If you discover content in the Research Portal that you believe breaches copyright or violates any law, please contact openaccess@qub.ac.uk. 


\title{
The Impact of Thermal Mass on Building Energy Consumption
}

\author{
Aidan Reilly ${ }^{\mathrm{a}, \mathrm{b}}$, Oliver Kinnane ${ }^{\mathrm{b}}$ \\ ${ }^{a}$ Department of Architecture, Queen's University Belfast, Northern Ireland \\ ${ }^{b}$ School of Architecture, Planning and Environmental Policy, University College Dublin, \\ Ireland
}

\begin{abstract}
This paper presents new metrics to measure the effect of thermal mass on the energy required to heat and cool buildings. Previous studies have been flawed as they have not considered the interaction between intermittent occupancy and thermal mass, which has a significant impact on overall energy use. However, existing parameters do not adequately capture these effects, so the new metrics developed in this paper are used to analyse the impact of thermal mass in hot climates with active cooling, and cold climates with active heating. The results agree with existing literature that high thermal mass structures are likely to be effective in hot climates; however, in cold climates the drawbacks of high thermal mass likely outweigh the advantages, and high thermal mass can cause an increase in energy use. This finding has implications for the design of buildings in cold climates, and contradicts the commonly-held assumption that high thermal mass is correlated with low energy use. The new metrics (transient energy ratio and effective U-value) provide a generalisable method to quantify these effects. They are further used here to analyse the dynamic performance of heavily insulated buildings and show that high thermal mass often leads to higher energy use in cold climates.

Keywords: thermal mass, heating, cooling, air conditioning, intermittent occupancy, transient energy ratio
\end{abstract}

Email addresses: a.reilly@qub.ac.uk (Aidan Reilly), oliver.kinnane@ucd.ie (Oliver Kinnane) 


\section{Contents}

1 Background 4

2 Measuring thermal mass $\quad 8$

2.1 Existing metrics . . . . . . . . . . . . . . . . . . 9 9

2.2 New parameters . . . . . . . . . . . . . . . 9

3 Thermal mass in a hot climate 11

3.1 Model details . . . . . . . . . . . . . . . . . . . 12

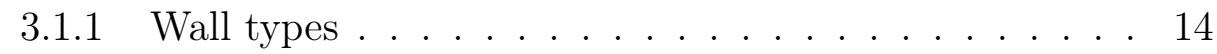

3.2 Results and discussion . . . . . . . . . . . . . . . . . . 14

4 Thermal mass in cold climates $\quad 19$

4.1 A cavity wall example . . . . . . . . . . . . . . . 20

4.1 .1 Model details . . . . . . . . . . . . . . . . 21

4.1.2 Results..................... . . . 22

4.2 Analysis of a retrofit to the Passivhaus standard . . . . . . . . 23

4.2.1 Results of retrofit study . . . . . . . . . . . 24

4.3 Evaluation of the TER for cool winter analysis . . . . . . . . 27

4.4 Comparison with Experiment . . . . . . . . . . . . . 27

4.4.1 Experimental Background ............ . . 27

4.4.2 Results.................... . . 29

5 Conclusions and evaluation $\quad 30$

6 Acknowledgements 31

A Details of the Finite Element Model 33

A.1 Solving the Heat Equation . . . . . . . . . . . . . . . 33

A.2 Run Time, Mesh Density and Timesteps . . . . . . . . . . . . 34

\section{List of Figures}

1 Modelled scenarios. In Scenario 1, the heat gain during the day is balanced by the heat loss at night. In Scenario 2, the nighttime heat loss is smaller as it is partially offset by the air

conditioning heat transfer during the day. . . . . . . . . 14 
2 Schematic view of the modelled walls; left: timber wall (for Madrid); centre: blockwork wall (for Madrid); right: cavity wall (used for Belfast, in Section 4) . . . . . . . . . . . . . . 15

3 Indoor wall surface temperatures for a timber building and a solid-wall (blockwork) building . . . . . . . . . . . . . . 17

4 Representation of temperatures within a thermally light and thermally heavy wall . . . . . . . . . . . . . . . 17

5 Wall surface temperatures for a blockwork wall with air conditioning running between $11 \mathrm{am}$ and $4 \mathrm{pm}$. . . . . . . . . . . 18

6 Wall surface temperatures for a static analysis of the blockwork wall, with air-conditioning running . . . . . . . . . 19

$7 \quad$ Surface temperatures for a timber wall (dynamic analysis, with air-conditioning from 11 am to $4 \mathrm{pm})$. . . . . . . . . 20

8 Temperature profile for October and November for a cavity wall 24

9 Indoor temperature, showing asymptotic temperature rise . . . 26

10 Temperature profile for the steady-state analysis for the two well-insulated walls . . . . . . . . . . . . . . . . 27

A1 Temperature profile at three mesh spacings . . . . . . . . . 35

A2 Section through the trial wall at three different mesh spacings 35 


\section{Background}

It is taken as self-evident that a reduction in the energy required to heat and cool our homes, offices, factories and other buildings is an important goal. To this end, engineers and architects worldwide incorporate energy efficiency measures at many stages of the design, whether for a new build or a refurbishment project; and greater awareness of global warming and climate change means that energy efficiency measures have taken on a greater prominence than, perhaps, at any time previously. Such thinking is incorporated into building design codes and regulations in the majority of developed states; however, many codes - and designers - focus primarily or entirely on the thermal resistance (or transmittance, the 'U-value'), to the exclusion of thermal mass[1].

The thermal mass of a building determines its ability to store heat energy, as either sensible or latent heat, and this in turn can have a large influence over indoor temperatures, power requirements and occupant comfort. By analogy with electrical circuits, the term thermal capacitance has gained wide currency, referring to the effect that large heat capacity components can have, buffering temperature changes and reducing the rate of change. Thermal mass is of importance during transient heating and cooling; this is also the dominant thermal mode for the majority of buildings globally, with comparatively few operating in anything like continuous, steady-state conditions. Domestic buildings occupied by working households, for example, might only be heated/cooled outside working hours, while the opposite might be true for office buildings.

There are three contributions to the thermal mass of a structure as a whole: the envelope and structural elements, the air volume, and the fittings, furniture and other objects. That the thermal mass of the building envelope is important, is easily shown by a simple calculation of the heat capacity of a typical room or building: the heat capacity of the air in a room of $25 \mathrm{~m}^{2}$ would be around $75 \mathrm{~kJ} / \mathrm{K}$, whereas the heat capacity of the building structure for such a room might be of order $20000 \mathrm{~kJ} / \mathrm{K}$ (see page 10). Interestingly, the heat capacity of the fittings, furniture and other contents might be of order $1500 \mathrm{~kJ} / \mathrm{K}$, and will vary greatly depending on the building's use. There is an increasing body of research looking at the effect of furniture on indoor temperatures, and this will have an effect, but is usually discounted from both simulation and experimental studies due to its variability[2, 3]. Neglecting, for the present study, the effects of the contents, it is clear that transient 
Contributions to the heat capacity of a typical room

Each element of a room makes a contribution to the total heat capacity. To make an order of magnitude estimate of the relative contributions, it is sufficient to take the volumetric heat capacity of air as $1.2 \mathrm{~kJ} / \mathrm{m}^{3} / \mathrm{K}$, and that for the walls as $1 \mathrm{MJ} / \mathrm{m}^{3} / \mathrm{K}$ (construction materials have a typical range of about 0.9 to 1.4 ). Using the relationship total heat capacity is volumetric heat capacity times volume, and assuming a square room of side length $5 \mathrm{~m}$, height $2.5 \mathrm{~m}$, and wall thickness $0.3 \mathrm{~m}$ gives $75 \mathrm{~kJ} / \mathrm{K}$ for the air and $15 \mathrm{MJ} / \mathrm{K}$ for the walls; the floor and ceiling will add to this. The mass of furniture will vary substantially; taking $30 \mathrm{~kg}$ per $\mathrm{m}^{2}$ floor area as typical[3] and assuming this is mostly timber $(2 \mathrm{~kJ} / \mathrm{kg} / \mathrm{K})$ gives a figure of $1500 \mathrm{~kJ} / \mathrm{K}$.

thermal behaviour is dominated by the heat capacity of the structure rather than that of the air.

Despite the importance of thermal mass, it remains an under-researched area by comparison with thermal resistance/conductivity. From the perspective of material performance, research has been carried out into the dynamic performance of individual structural materials, but even common structural materials such as concrete are not yet fully understood[4]. There are agreed standards relating to the dynamic thermal performance of building components ([5], and see also [6] relating to summer cooling), but these have failed to produce accurate results when compared to real data, perhaps due to the use of sinusoidal temperature profiles in the calculation procedure[7]. Where thermal mass is incorporated into building codes, it is often done so conservatively, or inappropriately[8]; many national building codes make no provision for thermal mass, restrict its use to cooling cases, or make no allowance for interactions between climate, occupancy and thermal mass (e.g. [9, 10, 11]). In terms of design and modelling, Kosny and Kossecka[12] showed that many simulation programs and codes provide inadequate results when modelling high-mass buildings, as they were developed for and tested with structures with much lower thermal storage capacity. An additional shortcoming is that many recent studies have been carried out using detailed simulation of one or a few buildings, sometimes combined with experiment; while these are likely entirely correct for the specific buildings and regions analysed, due to the very detailed nature of such work it is difficult to extrapolate from these studies to general conclusions[13, 14]. A few parametric studies have been carried out to understand the influence of thermal mass on buildings in a 
more structured fashion; for example, Aste et al [15] carried out a parametric study for a number of wall types, for heating and cooling cases; however, while useful, their study was restricted to a climate corresponding to that of Milan, Italy; and Asan[16] carried out a study into the effect of wall material and thickness on lag time and decrement factor for a wide range of homogeneous walls. A small number of studies have looked at the effects of varying the placement of insulation and thermal storage layers within a wall, usually relying on $1 \mathrm{D}$ studies and controlling for wall thickness[17, 18].

A drawback common to all these studies is the lack of a unifying framework for assessing thermal mass. A number of attempts have been made to develop such a framework, such as the 'M factor' method and the 'DBMS' method; intended primarily for $\mathrm{HVAC}^{1}$ equipment sizing and cooling climates, respectively, these methods have their applications but also significant drawbacks[19]. In particular, they neglect to allow for intermittent heating, which radically alters the impact of thermal mass. The underlying issue with developing a common framework, is the fundamental nature of transient behaviour by comparison with steady-state behaviour. While thermal conductivity is well-defined, with both length-independent ('thermal conductivity') and length-dependent ('U-value'/'R-value') measures that may be optimised, such parameters are lacking for dynamic thermal behaviour. Thermal diffusivity does not perform an equivalent role to conductivity; the nearest equivalent so far, is perhaps the time constant for a wall[20]. This has been used for parametric studies, but is not generalisable to multi-layer wall structures such as those common in modern construction[21][22]. This is of particular concern for models using lumped-mass methods of thermal analysis, which are popular but cannot adequately account for multi-layer behaviour unless each layer is treated separately; these problems are most apparent with low-order models, and at large Biot numbers[23, 24, 25, 26].

Furthermore, there is a lack of research focussing on the performance of thermal mass in temperate and cold climates. Where research exists for temperate climes, the focus again is on detailed models of specific buildings making it hard to generalise[13, 27]. Studies attempting to produce general results often involve unrealistic assumptions[28]. Many novel concepts have been proposed, some have been studied (e.g. [29, 30, 31, 32]), but again, detailed studies of a limited range of buildings produce results that are hard

\footnotetext{
${ }^{1}$ Heating, ventilation and air conditioning
} 
to generalise. In the case of the referenced studies, the latter looks primarily at high mass as a means to reduce overheating, even in a mid-European clime (the Netherlands) - but in many parts of the world, including mid and northern Europe, the quantity of energy used for heating is far greater than that used for cooling.

Given the lack of a unifying framework, the research that does exist relating to cold climates is patchy and contradictory. Bojić and Loveday[18] examined the influence of thermal mass and insulation on energy requirements for intermittent heating, intermittent cooling and continuous cooling cases, with various positions of the insulation/masonry layers in a combinedmaterial wall. They found that the greatest benefit from high thermal mass was found with an intermittent cooling case, where substantial reductions in energy use were found; in the case of continuous cooling there was no reduction in total energy use, though there was a reduction in the maximum cooling power requirement. In the intermittent heating case, thermal mass was found to increase the energy required. This is in line with other research (eg. [27], and Tsilingiris' development of the time constant by defining anisotropic time constants[33]), and contradicts the assumption in many quarters that increased thermal mass causes a reduction in heating requirements. Where studies have found increased heating energy use due to high thermal mass, these results are often not followed up (many of these results being 'corner cases' such as occasional winter heating in cooling-dominated climates[14, 34]).

Unfortunately, despite the importance of thermal mass, there are few studies looking at its effects in a generalisable, quantifiable sense. Much of the guidance aimed at building designers is of the form "thermal mass is good', when its inappropriate use in some cases is a hindrance, increasing energy consumption rather than decreasing it[20]. Published research as well as advice from governments and industry bodies can be confused, or simply wrong, about the benefit of thermal mass[35, 36, 37]. To a large extent, this can probably be attributed to two factors: firstly the relative complexity of modelling thermal mass compared to thermal resistance, and secondly the more involved nature of its effects. It is easy to understand the impact of thermal resistance on heat loss or gain through a wall envelope in a qualitative sense: increase the resistance, and heat flow drops. However, the effects of thermal mass are more subtle than the effects of resistance, and depend on a wider range of factors; such factors include not just average temperatures but also occupancy patterns, external temperature profiles, and details of the 
wall construction. It is also comparatively easy to model thermal resistance quantitatively, at least in a simplified form; whereas the impact of thermal mass is more difficult and time consuming to model, requiring transient numerical analysis or analytically complex methods[12, 15, 18, 28, 38, 39]. The lack of a single parameter for quantifying the dynamic properties of thermal mass is a definite drawback in this regard. This paper sets out to present just such a parameter, and to use it to analyse the impact of thermal mass in both hot and cold climates.

\section{Measuring thermal mass}

As discussed in the preceding section, there is much commentary regarding the purported positive effects of thermal mass, but less discussion of the drawbacks. One case, however, that has been noted in the literature as a scenario where thermal mass is a drawback, is the case of a weekend holiday home in a cold environment[20]. In a qualitative sense, this is easy to understand: our hypothetical building has been unoccupied for weeks or months; the occupants arrive late on a Friday evening, and turn on the heating system, leaving it running until they leave on Sunday. In this case, it is clear that a high thermal mass building will require more energy to heat than a low thermal mass building of identical floor area, U-value and air-tightness. The air inside warms up to the setpoint, and the building fabric continues to draw heat from the interior, placing a greater demand on the heating system. A substantial proportion of this heat will be returned to the building's interior - but this will happen on Sunday night and Monday, after the occupants have left, and is of no benefit. Hence, this represents wasted energy. Of course, a qualitative analysis only takes one so far, and what is really needed, is a way of quantifying this phenomenon. Unfortunately, one cannot use any material property, nor even the total thermal mass of the

building, since the proportion of extra heat required depends on the order of layers in the wall (as well as on details of the thermal loading case applied). It would be possible to develop a full, numerical simulation of a particular dwelling, but then the results would be very restricted in application. This paper proposes a more generalisable parameter, which is described in the following sections. 


\subsection{Existing metrics}

In terms of thermal performance, materials are characterised by two key parameters: thermal conductivity and heat capacity. For a steady-state analysis, the conductivity is the only one that is relevant, and the use of U-values makes such an analysis very easy: to optimise the steady-state thermal performance of a wall, it is necessary to minimise the U-value (or, for scenarios where heat transfer is desirable, to maximise it). Unfortunately, it is not so obvious how to optimise the thermal mass, nor even what parameter should be optimised. Studies focussed on thermal storage often emphasise the importance of both high heat capacity and high conductivity, in order to 'activate' the thermal mass[40], but there is a clear conflict here with the need to lower the conductivity to reduce overall heat loss/gain. Higher conductivities can, indeed, result in greater thermal storage, but they will also result in a greater heat flow to the outside (when used in an external wall). The time constant is related to the diffusivity, but this is also an unsuitable parameter, as two materials can have identical diffusivities but very different heat capacities, provided the conductivities also differ by the same factor (see box on page 10).

\subsection{New parameters}

An analysis of the steady-state performance of a wall, characterised by its thermal conductance, relies only on the mean temperature difference across the wall. This analysis may be performed either statically, using the mean temperatures for the season of interest, or quasi-statically, where the calculation is performed on a daily or hourly basis but the wall is assumed to remain in thermal equilibrium with the boundary conditions at all times. The use of a quasi-static analysis readily lends itself to integration in the degree-days model of heating demand[42]. For a particular wall type and thermal profile, it is also possible to carry out a full transient thermal analysis of a building element; this captures the effect of thermal mass, and the interday correlation of temperatures not accounted for in more simplistic analyses. Such an analysis (for actual building geometries) is typically carried out using a numerical simulation technique, of which there are many different variants.

In order to assess the role of thermal mass, it is useful to separate all the factors that influence the dynamic response of a building, and thus exclude extraneous factors such as ventilation rate, air volume, wall to floor area and other factors which would be included in a full building assessment. By modelling an individual construction element in isolation, the effects of 
Example diffusivity data

Thermal diffusivity is the property $\alpha$ :

$$
\alpha=\frac{k}{\rho c}
$$

$c$ here is the specific heat capacity; this is often given as the specific heat capacity at constant pressure $\left(c_{p}\right)$ or constant volume $\left(c_{v}\right)$, though for most solids there is little difference between the two values. Data is given for two example materials in the table below; concrete and PVC foam have very different conductivities and heat capacities, yet their diffusivities are similar. (Data from [41].)

Example material data:

\begin{tabular}{|l|c|c|c|c|}
\hline & $\begin{array}{c}\alpha \\
\mathrm{mm}^{2} \mathrm{~s}^{-1}\end{array}$ & $\begin{array}{c}k \\
\mathrm{~W} \mathrm{~m}^{-1} \mathrm{~K}^{-1}\end{array}$ & $\begin{array}{c}\rho \\
\mathrm{kg} \mathrm{m}^{-3}\end{array}$ & $\begin{array}{c}c \\
\mathrm{~J} \mathrm{~kg}^{-1} \mathrm{~K}^{-1}\end{array}$ \\
\hline $\begin{array}{l}\text { Cast concrete } \\
\begin{array}{l}\text { Polyvinyl } \\
\text { chloride foam }\end{array}\end{array}$ & 0.61 & 1.28 & 2100 & 1007 \\
0.64 & 0.035 & 37 & 1470 \\
\hline
\end{tabular}

thermal mass can be observed. These effects can be assessed by comparing an accurate, transient model which accounts for thermal mass effects, to a static model based purely on conductivity values. In order to do this, here we introduce the concept of the Transient Energy Ratio (TER): this ratio is defined as the energy used in a dynamic model of the scenario, divided by the energy used in the same scenario modelled with a quasi-static analysis (Equation 2).

$$
\text { T.E.R. }=\frac{\text { Energy used in a transient model }}{\text { Energy used in a static model }}
$$

The TER captures the effect of thermal mass, whether positive or negative, and separates it from steady-state performance.

It also becomes useful to define the concept of an effective U-value $\left(U_{e}\right)$. Relating energy use to U-values allows easy comparison between dynamic and static analyses. Reporting a dynamic response in the same units as a static response allows for appropriate comparisons, and as the building industry is generally very familiar with (static) U-values these are a useful choice. The effective U-value gives the correct result for the energy lost 
through the wall in a transient analysis; it is defined in Equation 3. Under steady-state conditions, $U_{e}=U$. This also applies for a 'thermally light' wall, i.e. one in which there are no thermal mass effects. Under non-steady conditions, a 'thermally heavy' wall will exhibit an effective U-value that differs, perhaps substantially, from the value calculated assuming steadystate conditions prevail.

$$
U_{e}=\frac{E}{A\left(\bar{T}_{o}-\bar{T}_{i}\right)\left(t_{2}-t_{1}\right)}
$$

In Equation 3, $E$ is heat flow, defined as positive when flow is from the outside to the inside of the wall; $A$ is wall area, and $t_{1}$ and $t_{2}$ are the start and end times. $\bar{T}_{o}$ and $\bar{T}_{i}$ are the mean outdoor and indoor temperatures, respectively, for the time period under study. Hence, $\bar{T}_{o}-\bar{T}_{i}$ is the mean temperature gradient causing heat flow through the wall (as in Equation 4). In the case of a hot climate, this term will generally be positive; in a cold climate, this term and the energy $E$ will be negative.

$$
\bar{T}_{o}-\bar{T}_{i}=\overline{\left(T_{o}-T_{i}\right)}
$$

The effective conductivity can also be defined. For a homogeneous wall, the relationship between the conductivity and the effective conductivity is the same as that between $U$ and $U_{e}$. For a non-homogenous wall it is not useful, and the use of $U$ and $U_{e}$ is preferred. The effective conductivity is related to $U_{e}$ as in Equation 5 .

$$
k_{e}=U_{e} \cdot L
$$

\section{Thermal mass in a hot climate}

Firstly, a wall section was analysed in August in Madrid, Spain: this is a hot region with a large temperature variation between day and night. An area with temperatures above the comfort zone during the day and below it at night is the classic situation in which thermal mass is expected to perform well; a high thermal mass wall will, it is anticipated, absorb much of the heat during the day and release it at night. The transient energy ratio measures the energy flow through a wall, by comparison with an equivalent wall with the same thermal resistance but zero heat capacity (i.e. no thermal mass). Consequently, for a scenario such as this, the TER is expected to be less than one - perhaps substantially less. 
Table 1: Madrid weather data[43, 46]

\begin{tabular}{l|c|c|c|c}
\hline & $\begin{array}{c}\text { Maximum } \\
\mathrm{K}{ }^{\circ} \mathrm{C}\end{array}$ & $\begin{array}{c}\text { Minimum } \\
\mathrm{K}{ }^{\circ} \mathrm{C}\end{array}$ & $\begin{array}{c}\text { Mean } \\
\mathrm{K}{ }^{\circ} \mathrm{C}\end{array}$ & $\begin{array}{c}\text { Mean diurnal range } \\
\mathrm{K}\end{array}$ \\
\hline 17-24 Aug. 2015 & 309.2 & 285.2 & 298.0 & 13.4 \\
& 36.0 & 12.0 & 24.8 & \\
\hline August mean & 308.8 & 286.8 & 298.9 & 16.5 \\
& 35.6 & 13.6 & 25.7 & - \\
\hline \multirow{2}{*}{ August extreme } & 314.4 & 280.6 & - & \\
& 41.2 & 7.4 & & 13.2 \\
\hline Annual & 315.4 & 258.0 & 287.7 & \\
& 42.2 & 15.2 & 14.5 & \\
\hline
\end{tabular}

The setting chosen for this analysis was a south-facing wall in August; Madrid has a hot, dry climate, with high solar gain conditions, well-suited to high thermal mass buildings. An arbitrary week was chosen, from 17th to 24th August 2015. Temperature data was obtained from aviation records for Madrid Barajas airport with a half-hourly resolution; solar flux data was estimated from data on the mean solar flux and sunshine hours per day for Madrid[43, 44]. The weather during the week modelled was typical of Madrid's climate[45] (see Table 1).

\subsection{Model details}

For this example, and the rest of this study, two models were used for each scenario, a static and a transient analysis. The static analysis ignores the contribution of thermal mass; in this analysis, the energy loss is calculated assuming that the wall is in steady-state conditions at all times. In other words, the temperature gradient within the wall is treated as piecewise linear, with the temperature gradient in each layer determined solely by the thermal conductivity. This gives an energy flow at any time that is in exact agreement with the U-value for the wall, i.e. Equation 6 holds. The temperature on the outside face of the wall was determined by the energy balance between heat received from the sun, heat lost (or gained) to (or from) the surrounding air, and heat flow towards the inside of the wall.

$$
E^{\prime}=U A\left(\bar{T}_{o}^{\prime}-\bar{T}_{i}^{\prime}\right)\left(t_{2}-t_{1}\right)
$$

(This is similar to Equation 3; the symbol ' is used to denote that this is a steady-state analysis.) 
The dynamic analysis used a finite element (FE) model of the wall. The model was implemented in commercial finite element software ${ }^{2}$. The emphasis was on simplicity and making as few restrictive assumptions as possible, aiming to produce results of general applicability. For this reason, no assumptions were made that would restrict the model to any particular building volume, and thermal bridging and edge effects were not included. The model comprised a unit square with heat flowing in the through-thickness direction (with other boundaries insulated), with nodes at approximately 7 mm spacing on average (with a greater density in materials of high diffusivity and a lower density in the others). Internal connections between materials were tied. A maximum and default timestep of $900 \mathrm{~s}$ was used, which was reduced as necessary during periods of steep temperature changes to give a maximum temperature change per step at any node of $0.1 \mathrm{~K}$. Further details of the FE model are given in Appendix A.

Two scenarios were modelled for each wall (corresponding to two different boundary conditions on the inside face). The two scenarios are illustrated in Figure 1. The first examined the temperature response of each wall during conditions of no heat flow; in this scenario, the boundary condition on the inner face allowed no heat exchange. Under these circumstances, a thermally light wall should quickly reach equilibrium with the outdoor temperature, while a thermally heavy wall will take longer. This is a useful model for developing understanding of the behaviour of different wall typologies, although it does not represent a physically realistic condition.

The second scenario was more realistic: in this, the wall's inner face was exposed to air at $299 \mathrm{~K}\left(26^{\circ} \mathrm{C}\right)$ between the hours of 9 am and $5 \mathrm{pm}$, and insulated outside these hours, as a model of a well-sealed office building with air conditioning. The insulated boundary provides a reasonable model of a well-sealed building, as the contribution of the air volume in the interior to the thermal mass is negligible (as discussed in Section 1).

Heat transfer between the wall and air was modelled according to ISO 6946 as in Equation 7. This equation produces a single, overall heat transfer coefficient $h$ which includes contributions from conduction, convection and radiation. Although this method is an approximation, the error (less than 1\%) was appropriate for this level of accuracy. Velocity and mean temperature data gave a value of $h=24.0 \mathrm{~W} \mathrm{~m}^{-2} \mathrm{~K}^{-1}$ for Madrid during this week[46]. The

\footnotetext{
${ }^{2}$ Abaqus/CAE $6.12-2$
} 
Scenario 1

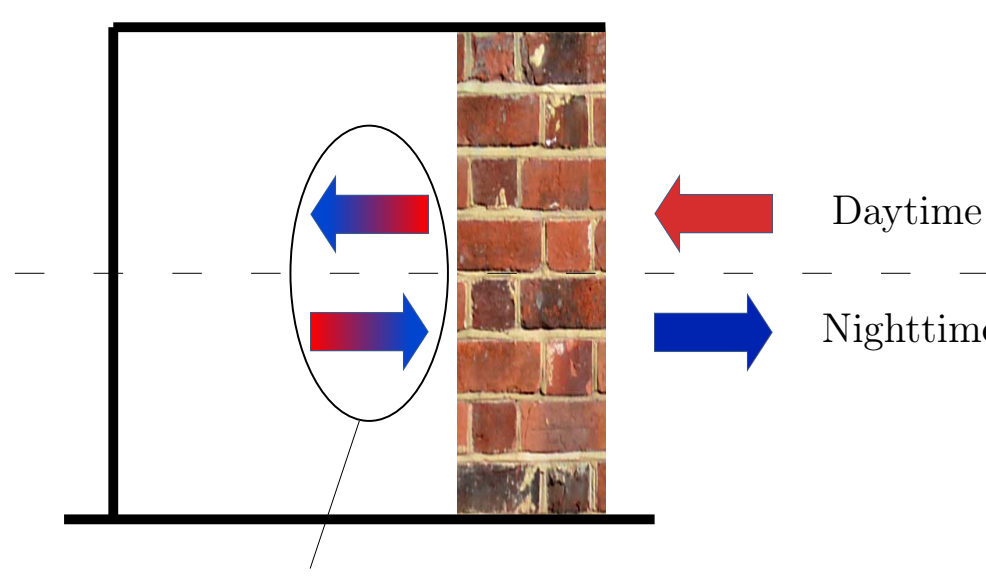

Equal heat transfer
Scenario 2

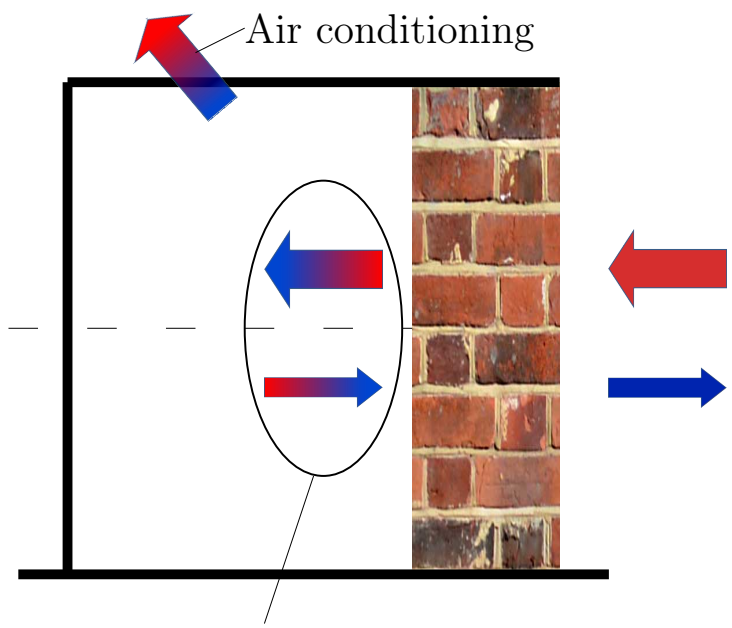

Unqual heat transfer

Figure 1: Modelled scenarios. In Scenario 1, the heat gain during the day is balanced by the heat loss at night. In Scenario 2, the nighttime heat loss is smaller as it is partially offset by the air conditioning heat transfer during the day.

solar flux was calculated at half-hourly intervals for a vertical, south-facing wall. The emissivity of the wall was chosen as 0.9 .

$$
h=(4+4 \bar{v})+4 \varepsilon \sigma_{0} \bar{T}_{o}^{3}
$$

\subsubsection{Wall types}

Two walls were modelled for this location, with comparatively high and low thermal masses. The high thermal mass wall was a solid blockwork wall, with internal plaster and external render, being representative of uninsulated construction. The low thermal mass wall was made from $20 \mathrm{~mm}$ of timber such as might be found in a shed or outbuilding. Schematics of the walls are shown in Figure 2; material properties and wall dimensions are given in Table 2.

\subsection{Results and discussion}

The static and dynamic analysis was conducted for the two wall types considered. The first heating condition was a simulation of the case of a wellsealed building with no air conditioning (nor heating). In this case, a steadystate ("static") analysis predicts the same temperature in the timber wall 
Table 2: Description and properties of timber and solid blockwork walls[41]

\begin{tabular}{l|c|c|c|c}
\hline Material & Conductivity & $\begin{array}{c}\text { Specific heat } \\
\text { capacity } \\
\mathrm{J} \mathrm{kg}^{-1} \mathrm{~K}^{-1}\end{array}$ & $\begin{array}{c}\text { Density } \\
\mathrm{kg} \mathrm{m}^{-3}\end{array}$ & $\begin{array}{c}\text { Thickness } \\
\text { used } \\
\mathrm{m}\end{array}$ \\
\hline Fir & 0.14 & 2720 & 419 & 0.02 \\
\hline Plaster & 0.52 & 840 & 1300 & 0.0125 \\
Blockwork & 0.44 & 650 & 1500 & 0.25 \\
Render & 0.79 & 1000 & 1322 & 0.02 \\
\hline
\end{tabular}

Values vary; those for render are quoted for a moisture content of $8 \%$, and for fir at a moisture content of $20 \%$. Data from Clarke et al[41].
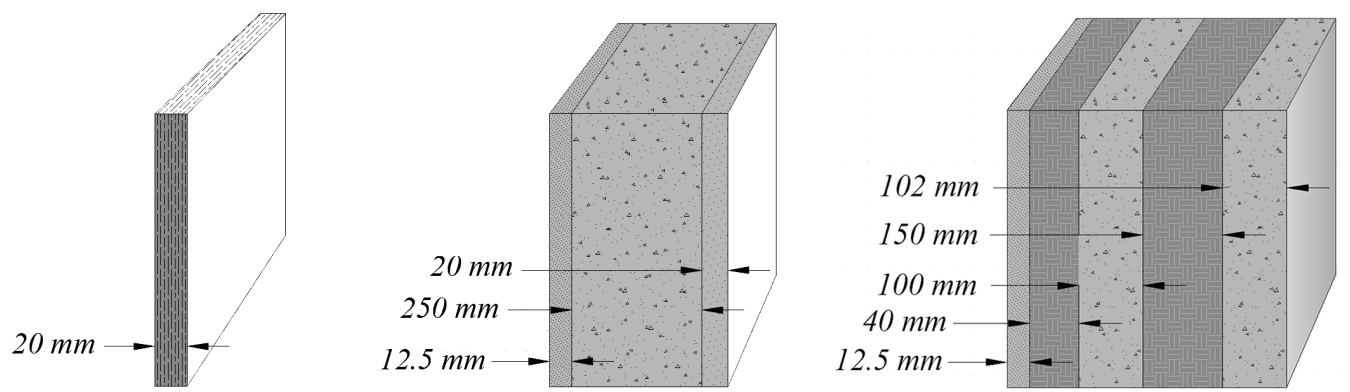

Figure 2: Schematic view of the modelled walls; left: timber wall (for Madrid); centre: blockwork wall (for Madrid); right: cavity wall (used for Belfast, in Section 4) 
and the blockwork wall: the energy balance, under steady-state conditions, is that all heat received from the sun is transferred to the surroundings. The wall's temperature is determined by the temperature at which heat gains and losses are in balance.

However, a dynamic analysis of the two walls produces very different results, and the response of the two walls is shown in Figure 3. When transient effects are taken into account in the dynamic model, the high mass, blockwork wall has an obvious and significant moderating influence on the temperatures. In this case, the energy balance at the outside surface contains three terms: a solar flux received, a heat loss to the air, and a heat flow into the wall. The substantial heat capacity of the blockwork wall results in a much lower temperature rise on the inside surface than in the case of the static analysis (Figures 3 and 4 ). In qualitative terms, the thermal mass has a significant effect. The dynamic analysis of the lightweight wooden wall falls between the extreme of the blockwork wall and the static analysis, exhibiting a slight temperature moderating influence but not nearly as much as the blockwork wall. The high mass wall provides not only damping, but also a timeshifting effect on the peak temperatures, and for this specific case the indoor temperature is almost in antiphase with the outside temperature. This is of benefit in terms of providing more comfortable indoor temperatures during the day, and so far, all is as expected.

Examining now the more interesting case of the second scenario, where air conditioning is employed to cool the interior space to a more comfortable temperature - such as $299 \mathrm{~K}\left(26^{\circ} \mathrm{C}\right)$ - during occupied hours. In this case, the static model no longer predicts a uniform wall temperature through the wall thickness: instead, it provides the steady-state solution between the resultant outside wall temperature ${ }^{3}$ and the indoor temperature, as a function of the wall's thermal conductance. Examining the high mass wall first, in Figure 5 where the interior temperature previously demonstrated something akin to a sine wave, it now shows a 'cut-off sine wave', with nearly flat regions during the time the air conditioning is operating. Over the course of the week modelled, this wall would allow a flow of $2.65 \mathrm{MJ} / \mathrm{m}^{2}\left(0.74 \mathrm{kWh} / \mathrm{m}^{2}\right)$ of heat into the building, heat which would then have to be removed by the air

\footnotetext{
${ }^{3}$ The resultant outside wall temperature is higher than the air temperature due to solar radiation. It is close to but not equal to the sol-air temperature; it would be equal to the sol-air temperature in the case of a perfectly insulating wall.
} 


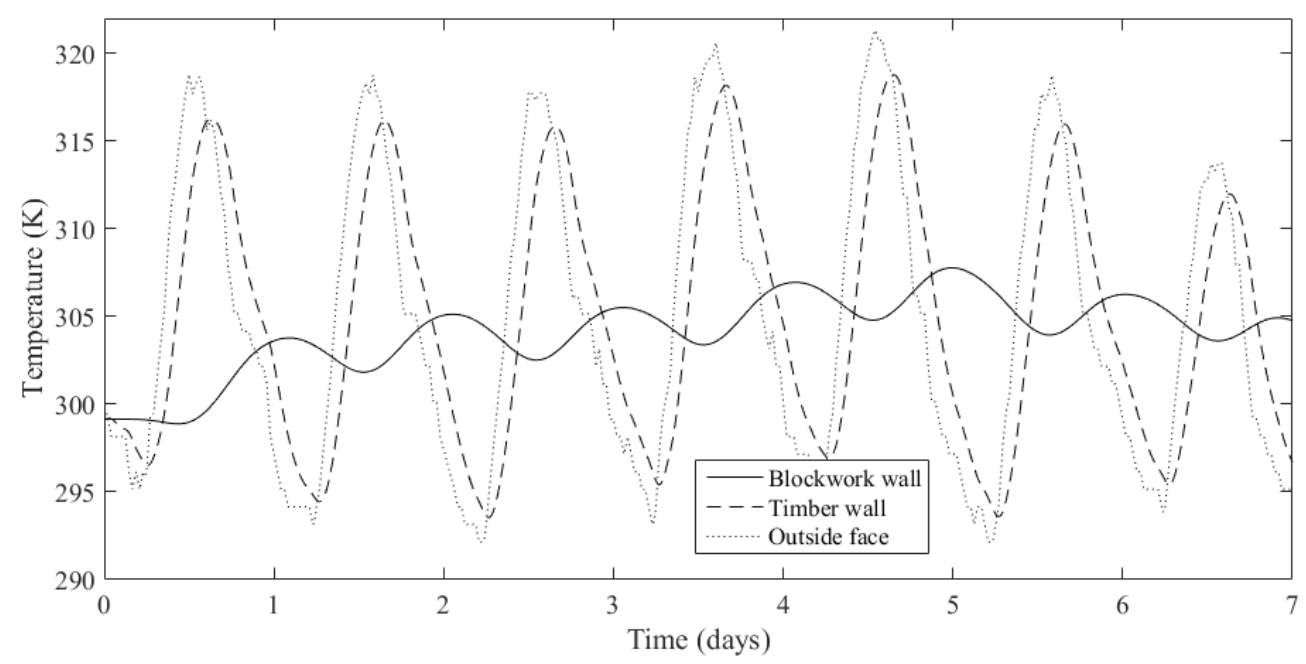

Figure 3: Indoor wall surface temperatures for a timber building and a solid-wall (blockwork) building

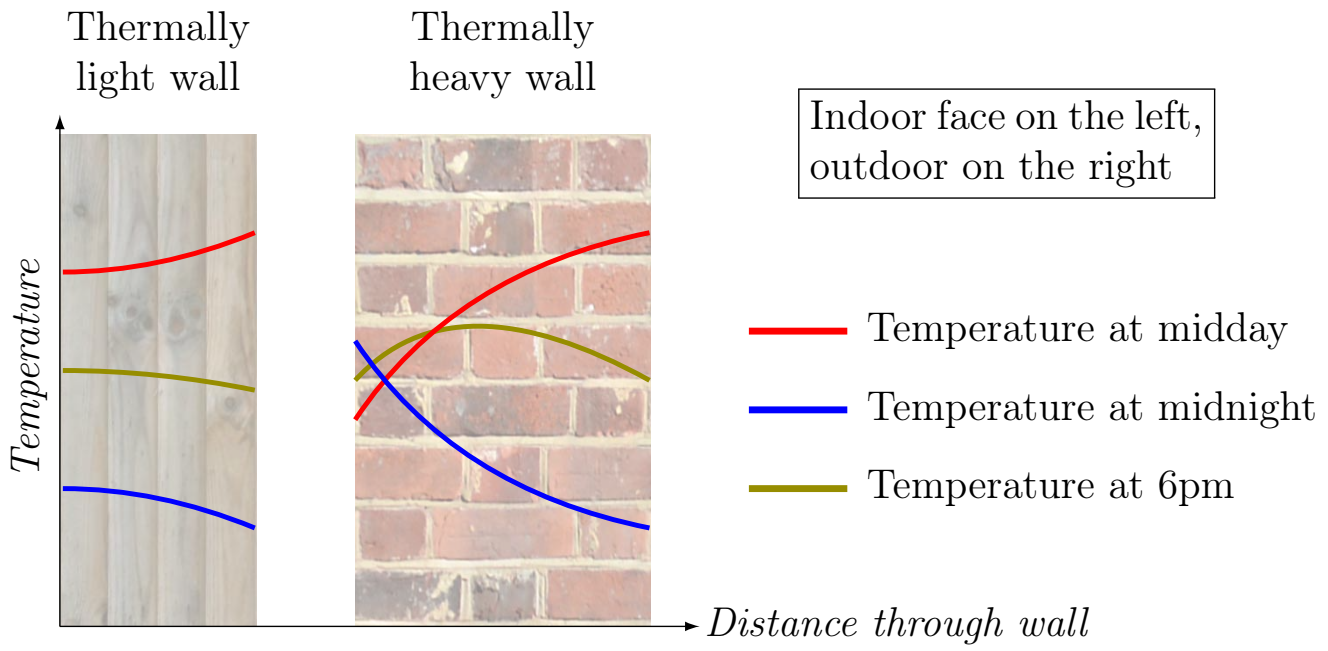

Figure 4: Representation of temperatures within a thermally light and thermally heavy wall 


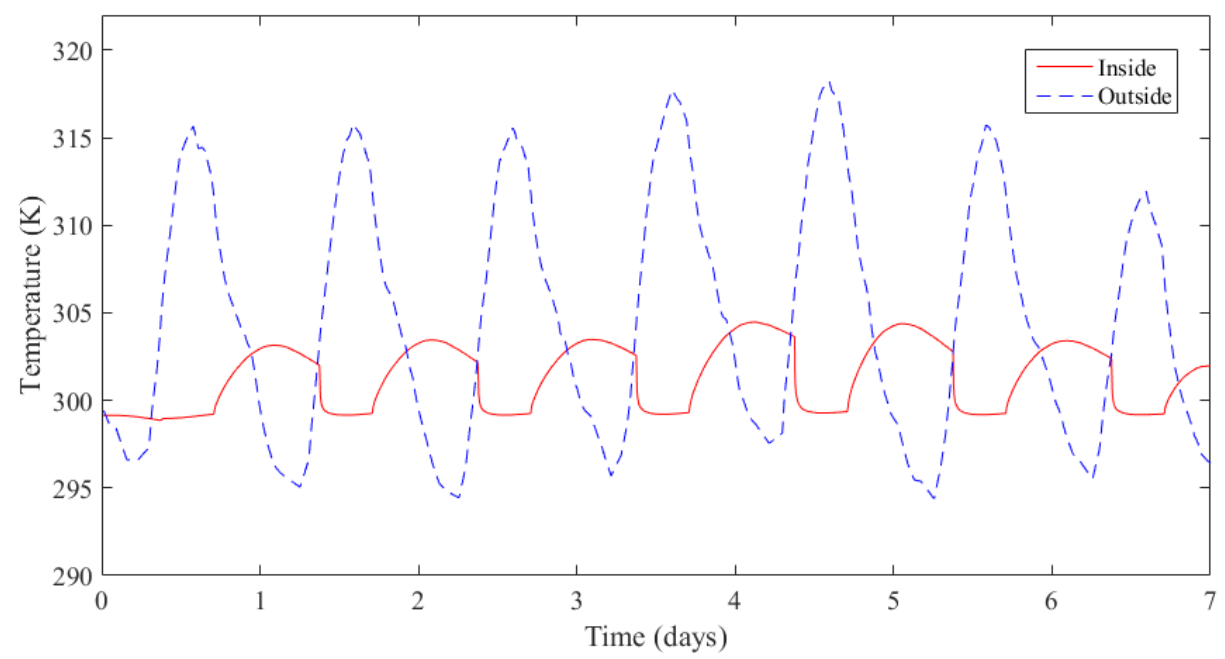

Figure 5: Wall surface temperatures for a blockwork wall with air conditioning running between $11 \mathrm{am}$ and $4 \mathrm{pm}$

conditioning system to maintain the set indoor temperature.

A static calculation, ignoring the thermal mass, was also carried out for this scenario. This is shown in Figure 6. In the static model, the wall is in quasi-equilibrium; that is to say, steady-state heatflow conditions prevail at all times within the wall; the end temperatures are not constant, as they respond to the inside and outside air temperatures, and solar gain. (The slight aliasing seen in these results in the figure is a result of the half-hourly resolution in weather data.) When the interior is not cooled, the steadystate condition is that the inside and outside are at the same temperature (as shown). During periods of cooling, a temperature gradient exists in the wall, and there is heat flow through it. Like earlier for the dynamic analysis, this heat flow represents a cooling load on the building systems.

The inward heat flow in the static model, over the course of the week, is $4.55 \mathrm{MJ} / \mathrm{m}^{2}$. Combined with the value from the dynamic analysis, and using the definition given in Equation 2, this gives a transient energy ratio of 0.58. This is significantly less than one: this indicates that this wall type is responding dynamically to the thermal loading. The degree of departure from one indicates the divergence between the static and dynamic models, and in this case suggests that calculations based on a static analysis of the wall as would typically be done during design, using wall U-values — would be 


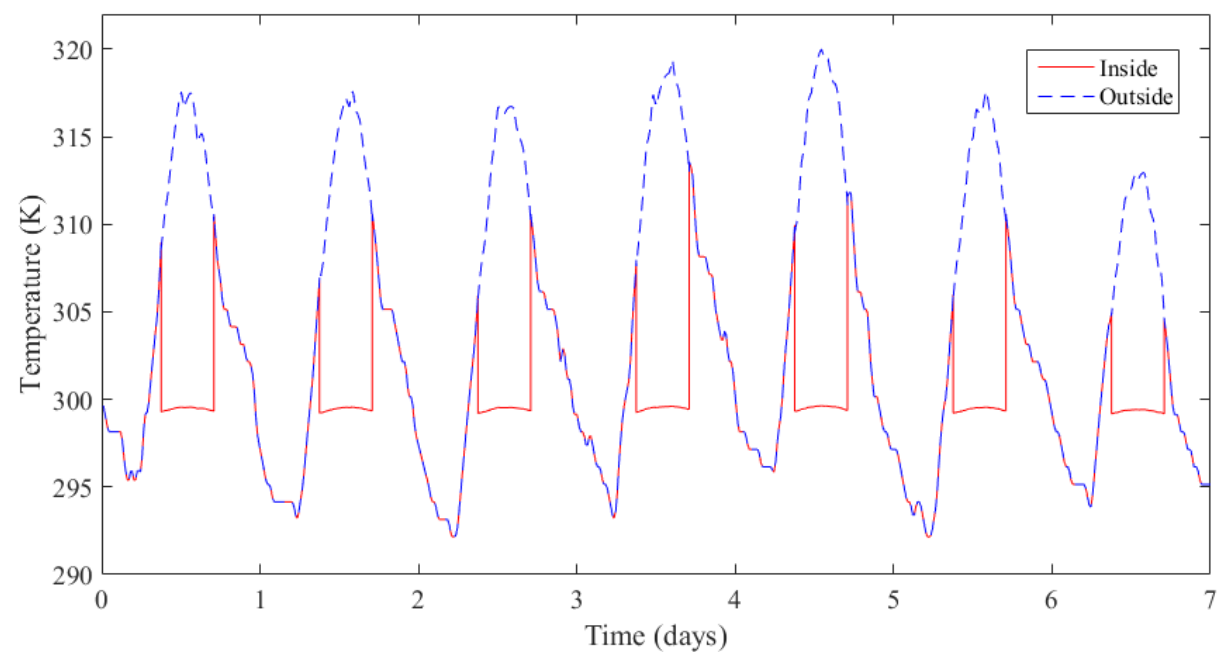

Figure 6: Wall surface temperatures for a static analysis of the blockwork wall, with air-conditioning running

inaccurate. In this case, the consequences may not be so severe, and as the energy used will be lower than the naïve static prediction the worst consequence might be an oversizing of building services. On the other hand, if this effect is not taken into account in an existing building, it could be a significant contribution to the rebound effect, leading to poor retrofit decisions. (See [47] for a discussion of the rebound effect in relation to retrofit.)

Similar analyses were undertaken for the wooden wall, and these results are presented in Figure 7. The static and dynamic models predict heat inflows in this case of 9.22 and $8.58 \mathrm{MJ} / \mathrm{m}^{2}$, giving a TER of 0.93 . In this case, the thermal mass of the thin wall is much less significant. Retrofit and policy decisions made on the basis of static calculations will be more reliable, although detailed design work might still be advised to take dynamic effects into account, or else errors of the order of $7 \%$ can be expected.

\section{Thermal mass in cold climates}

In the previous section, the TER was used to quantify the effects of thermal mass for hypothetical structures in a hot climate with high diurnal variation; turning now to a cold climate, one example of a structure where thermal mass effects play a large role in indoor comfort is a building with short occu- 


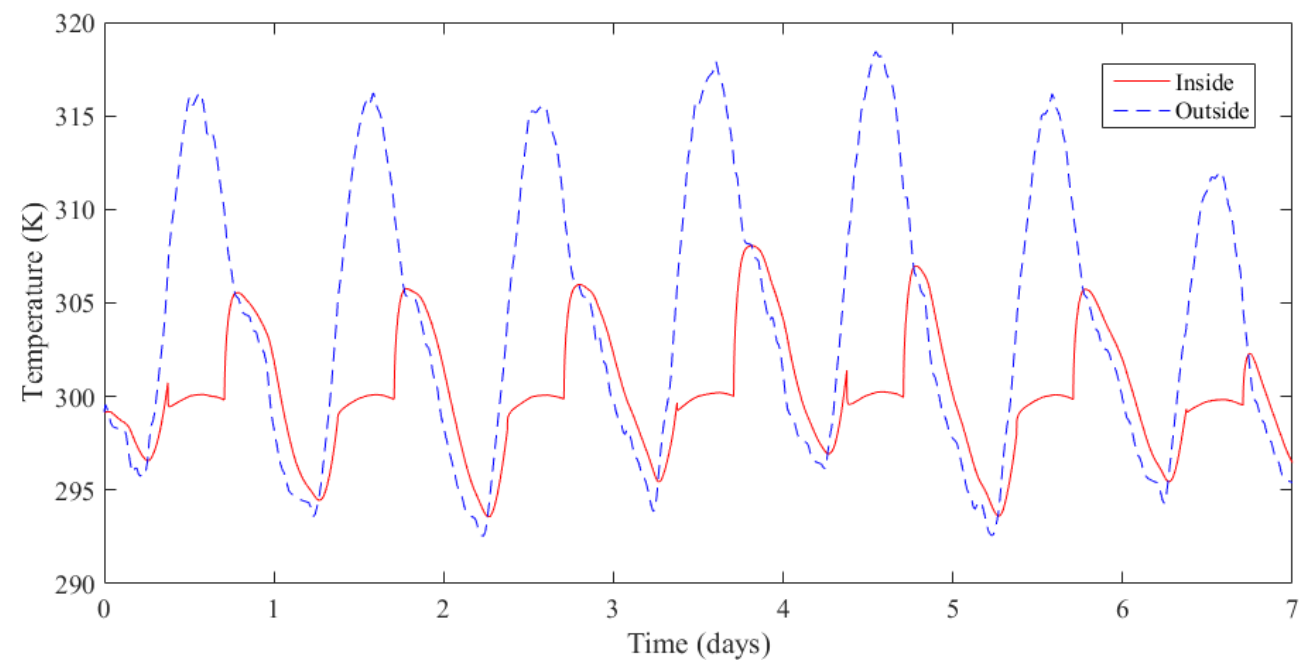

Figure 7: Surface temperatures for a timber wall (dynamic analysis, with air-conditioning from 11am to $4 \mathrm{pm}$ )

pancy hours - for example, weekend holiday homes, or other structures with very low occupancy. Such structures have been used in the literature as examples of buildings where thermal mass is a drawback[20]. However, weekend holiday homes form a very small fraction of the total building stock. As the same effects may occur with other buildings, more widespread use patterns are considered here. Take the case of an office building, and assume that the heating is optimised to minimise energy use whilst maintaining a comfortable temperature: the heating system turns on at some defined time to provide a period of preheating before occupied hours, the building is heated during that time, and then cools during the evening and overnight, to be heated again the following morning. Although the effect of thermal mass in this case is not likely to be as dramatic as for a weekend cabin, it is still present, and can be quantified. Thermal mass effects also occur with domestic buildings: in cool climates, these are often heated for a short period in the morning and a longer period in the evening, and are unheated outside occupied hours.

\subsection{A cavity wall example}

The first example presented here is representative of a typical office building in a cool maritime climate. The location chosen was Belfast, Northern Ireland; Belfast has a cool, maritime climate, and the use of central heating 
Table 3: Cavity wall description and properties

\begin{tabular}{l|c|c|c|c|c}
\hline Material & Thickness & Conductivity & $\begin{array}{c}\text { Heat } \\
\text { capacity } \\
\mathrm{J} \mathrm{kg}^{-2} \mathrm{~K}^{-1}\end{array}$ & $\mathrm{~kg} \mathrm{~m}^{-3}$ & $\begin{array}{c}\text { Density } \\
\mathrm{W} \mathrm{m}^{-1} \mathrm{~K}^{-1} \mathrm{~s}^{-1} \\
\times 10^{6}\end{array}$ \\
\hline Plaster & 0.0125 & 0.52 & 840 & 1300 & 1.71 \\
Insulation & 0.04 & 0.055 & 99 & 320 & 1.74 \\
Blockwork & 0.1 & 0.44 & 650 & 1500 & 0.451 \\
Cavity in- & 0.15 & 0.047 & 837 & 96 & 0.582 \\
sulation & 0.102 & 0.721 & 796 & 1920 & 0.472 \\
Brick & & & & \\
\hline
\end{tabular}

Note: for porous materials, it is not always appropriate to use a single value for these properties; building materials exhibit substantial variation in properties, and vary with moisture content, etc. In many cases the values above have been measured for complete building units, and so the use of the quoted values for the present study is considered valid. Values taken from Clarke et al[41].

in winter is near-universal. Historical weather data for Belfast was obtained from the UK Met Office, for the winter period from 1 October 2015 to 22 March 2016. The wall modelled was a cavity wall with parameters typical of construction in the late 20th century: details of the wall, along with the material properties, are given in Table 3. The occupancy pattern modelled was for occupancy between 9am and 5pm (to simplify the analysis, weekends and holidays were not treated differently). The internal air temperature was set to $294 \mathrm{~K}\left(21^{\circ} \mathrm{C}\right)$ during occupied hours, and allowed to float freely in response to the outside temperature outside this time.

\subsubsection{Model details}

For this model, it was assumed that the internal temperature was controlled by a perfect controller able to maintain the room at exactly the desired temperature. In reality, the assumption of a single temperature set point is not likely to be applicable. In domestic settings, a comparatively wide range of temperatures can be tolerated by most individuals, and by allowing the indoor temperature to float a reduction in energy use can be achieved; however, a single temperature provides a common baseline for comparing wall types and climates. Outside occupied hours, the internal surface was insu- 
Table 4: Energy used and TER for a sample wallt

\begin{tabular}{l|l|l|l}
\hline & $\begin{array}{l}\text { Energy used } \\
\text { in the static } \\
\text { model }\left(\mathrm{MJ} / \mathrm{m}^{2}\right)\end{array}$ & $\begin{array}{l}\text { Energy used in } \\
\text { the dynamic } \\
\text { model }\left(\mathrm{MJ} / \mathrm{m}^{2}\right)\end{array}$ & \\
\hline Cavity wall & 15.4 & 40.9 & 2.65 \\
\hline
\end{tabular}

lated, so the wall's temperature fell towards equilibrium with the outside air. Heat transfer between the wall and the air was modelled as in Equation 7; the mean wind speed $\bar{v}$ for the period in question for Belfast was $4.9 \mathrm{~m} / \mathrm{s}$ with a mean temperature of $287 \mathrm{~K}\left(14^{\circ} \mathrm{C}\right)$, giving $h=35.2$. Solar gain was not included, which is a reasonable model of a north-facing or shaded wall.

As for the case of Madrid, static and transient analyses were carried out for each scenario. The static analysis used the relationship given in Equation 6 , with the mean outside temperature calculated as the mean temperature during occupied hours for the period of study; the interior temperature was the setpoint temperature $\left(294 \mathrm{~K}\left(21^{\circ} \mathrm{C}\right)\right)$. The transient model used a similar model to that described in Section 3.1, adjusted in terms of geometry and boundary conditions to account for the changed conditions.

\subsubsection{Results}

The raw output from both models (static and dynamic) was an energy consumption over the model duration. This is the energy, per unit of wall area, that is required to maintain the setpoint temperature during occupied hours. For the dynamic model, this was calculated by examining the heat flow across the internal surface of the wall at each timestep, and integrating this for the 5 month period in question to give the total heating energy used. This energy use was converted to an effective U-value using Equation 3. The static U-value $(U)$ was calculated by the conventional method of summing resistances. ${ }^{4}$ The TER is the ratio of energy used in the dynamic case compared to the static case - the energies used, and the TER, are shown in Table 4. The energy used is expressed in terms of MJ per square metre of wall area.

The energy consumption in the static model is $15 \mathrm{MJ} / \mathrm{m}^{2}$. This is the energy that would be required if the wall had zero heat storage capacity.

\footnotetext{
${ }^{4} \mathrm{~A}$ steady-state model was run in the FE model for error checking, with a $0.5 \%$ error when compared to the hand calculation.
} 
Once thermal mass is taken into account, in the transient model, the energy consumption increases from 15 to $40 \mathrm{MJ} / \mathrm{m}^{2}$. From Eq. 2, the TER is equal to 2.65 - in other words, more than twice as much energy is needed as is predicted by a steady-state analysis. To facilitate comparison between different scenarios and wall types, these energies can be converted into effective U-values, as in Equation 3. For this example, $U=0.232 \mathrm{~W} \mathrm{~m}^{-2} \mathrm{~K}^{-1}$, which is fairly typical for standard cavity wall construction[9]. However, for the 5 month period modelled, dividing the heating power by the temperature difference according to Equation 3 gives an effective U-value, $U_{e}$, of $0.615 \mathrm{~W} \mathrm{~m}^{-2} \mathrm{~K}^{-1}$. This is the 'U-value' that is actually achieved in practice, for these climate conditions and this load case. A light wall, with negligible thermal mass behaviour, would not experience any delay in its response, and would match the static U-value result (since it would be in a quasi-steady state at all times). In the case of a wall with thermal mass, extra heat is needed to heat up the wall at the start of each day. Although this reduces the amount of heating needed the next day, the net effect is that more heat is lost overall - and this effect will always dominate[21, 48].

The amount of heat retained overnight can be seen by looking at the indoor temperatures each morning. On the warmest days, this is around $291 \mathrm{~K}\left(18^{\circ} \mathrm{C}\right)$; on the coldest, it falls to $288 \mathrm{~K}\left(15^{\circ} \mathrm{C}\right)$, which is around $15 \mathrm{~K}$ higher than the mean outdoor temperature that week (see Figure 8). This will reduce the power input needed in the morning, but this is not 'free heat' in any sense: it is heat that was provided by the heating system at an earlier time. In a Belfast winter, the effect of thermal mass is clearly detrimental, causing substantially increased energy use. The TER quantifies this effect: the energy use, for a typical office, is more than double that predicted by a static analysis.

\subsection{Analysis of a retrofit to the Passivhaus standard}

This model can be expanded to other scenarios, where it may be used to directly inform design decisions: consider now the case of solid walls used for domestic construction. While cavity walls are common in new house construction, buildings built before 1950 often have solid walls; and owing to the longevity of buildings there is substantial interest in improving the thermal performance of these older buildings[49]. Commonly, retrofits to solid-walled structures involve the addition of insulating material to the wall, leaving the original load-bearing structure intact. Insulation may be added internally or externally; although both may perform equivalently when compared in terms 


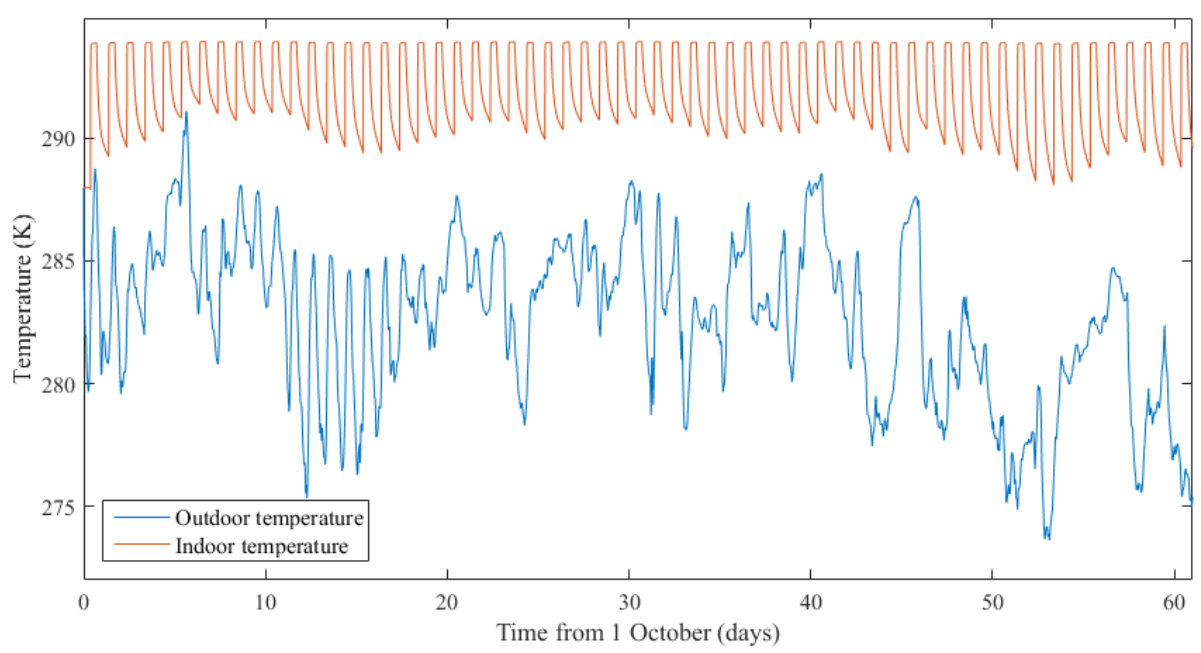

Figure 8: Temperature profile for October and November for a cavity wall

of the static U-value achieved post-retrofit, it is possible that a significant difference exists in terms of dynamic performance. Use of the TER and effective U-values generates a quantitative answer to the question of optimum insulation location. The study that follows includes three wall types: a solid wall, comprising plaster, concrete block, and render; and two designs that bring this wall up to meet the Passivhaus standard U-value of $0.15 \mathrm{~W} \mathrm{~m}^{-2} \mathrm{~K}^{-1}$ : one with internal insulation and one with external insulation. These two Passivhaus-standard cases required the addition of $332 \mathrm{~mm}$ of insulation to the inside and outside, respectively. The properties of the insulation were as in Table 3; the additional complications of vapour barriers, and thermal bridges, were not included[50]. These walls were modelled under a typical domestic use pattern, comprising morning and evening heating: 6:30am to $8 \mathrm{am}$, and 5pm to 9:30pm.

\subsubsection{Results of retrofit study}

Steady-state and transient predictions of the energy use were calculated, assuming the same conditions in both cases (an indoor temperature of $294 \mathrm{~K}\left(21^{\circ} \mathrm{C}\right.$ ) during occupied hours.) Based on the steady-state calculation, using the Uvalues for the walls of 1.62 for the solid wall and $0.15 \mathrm{~W} \mathrm{~m}^{-2} \mathrm{~K}^{-1}$ for the two Passivhaus-compliant walls, the energy use from October to March would be $108 \mathrm{MJ} / \mathrm{m}^{2}\left(27.9 \mathrm{kWh} / \mathrm{m}^{2}\right)$ and $9.99 \mathrm{MJ} / \mathrm{m}^{2}\left(2.78 \mathrm{kWh} / \mathrm{m}^{2}\right)$ respectively. 
Table 5: Passivhaus study energy use

\begin{tabular}{l|l|l}
\hline Wall & $\begin{array}{l}\text { Steady-state predic- } \\
\text { tion of energy use } \\
\mathrm{MJ} / \mathrm{m}^{2}\left(\mathrm{kWh} / \mathrm{m}^{2}\right)\end{array}$ & $\begin{array}{l}\text { Transient model pre- } \\
\text { diction of energy use } \\
\mathrm{J} / \mathrm{m}^{2}\left(\mathrm{kWh} / \mathrm{m}^{2}\right)\end{array}$ \\
\hline $\begin{array}{l}\text { Solid wall } \\
\text { Wall with internal in- } \\
\text { sulation } \\
\begin{array}{l}\text { Wall with external in- } \\
\text { sulation }\end{array}\end{array}$ & $\begin{array}{l}107.9(30.0) \\
9.99(2.78)\end{array}$ & $30.9(8.57)$ \\
\hline
\end{tabular}

Not surprisingly, there is a dramatic reduction in the predicted energy use when insulation is added; since in a steady-state analysis, heat flow is proportional to the U-value, the ratio of the energy used for the bare wall and the insulated walls is equal to the ratio of the U-values. However, this only tells half the story; as in the cavity wall example, substantially more energy is needed when the transient effect of thermal mass is included. As for the case of the office building, under intermittent occupancy, dramatically higher energy is required to maintain the indoor temperatures in the case of a transient model. The energy use for each wall is shown in Table 5.

As can be seen from the results, the plain solid wall uses more than twice as much energy as would be predicted by a steady-state analysis. While the insulated walls still perform much better than the uninsulated wall, they too use more energy than predicted by a steady-state analysis: around 3 times as much. Moreover, there is a $10 \%$ penalty in energy consumption for the external insulation case, as compared to the internal insulation case. Adding internal insulation reduces the temperature variation in the dense, high-heat-capacity layers of the wall, and hence reduces the overall energy losses.

There is a further penalty from having high thermal mass layers connected directly to the indoor space: the temperature response of the building is damped. Although this is often touted as a benefit of thermal mass in hot climates, it is a drawback when active heating is needed - as it is here. The mean difference between inside and outside temperatures is slightly lower in the high thermal mass cases, shown in the first column of Table 6. This difference arises as the lower the thermal mass in direct contact with the indoor air, the faster the surface temperature of the wall rises (see Figure 9).

The TER for the three walls is shown in Table 6 - this quantifies the 


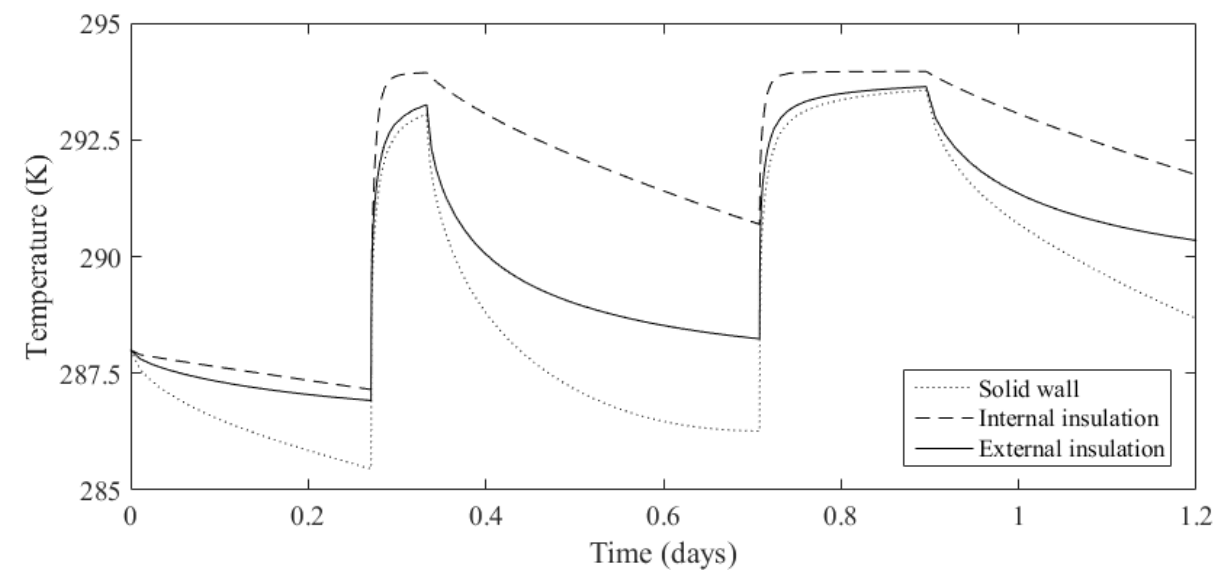

Figure 9: Indoor temperature, showing asymptotic temperature rise

divergence from steady-state conditions that applies in each case. From these results, it is possible to calculate the effective U-value $U_{e}$ (using Equation 3): this provides a useful comparison between the different wall types. While the TER measures the impact of thermal mass for each wall, to compare the different wall types $U_{e}$ is more useful: for example, although the solid wall has a lower TER than the two Passivhaus-compliant walls, the latter two walls still perform better by virtue of their enhanced insulation. $U_{e}$ takes account of the overall wall performance. From this table, it is clear that under transient loading these walls do not perform as a steady-state analysis suggests. While the static U-value is $0.15 \mathrm{~W} \mathrm{~m}^{-2} \mathrm{~K}^{-1}, U_{e}$ is around 3 times this for both insulated walls. The effective U-value of around 0.5 is not only far in excess of the Passivhaus standards, it is higher than typical minimum legal requirements for northern European construction[9].

Although both of the insulated walls perform poorly in a transient analysis, the wall with internal insulation performs substantially better than the wall with external insulation, with an effective U-value around $20 \%$ lower. In the case of external insulation, the structural section of the wall, with a large heat capacity, must be brought up to almost the temperature of the room. This is illustrated in Figure 10, which shows the steady-state temperature as a function of position through the wall: as the blockwork is very much more conductive than the insulation, external insulation causes the blocks to reach nearly room temperature; whereas with the insulation on the inside, the structural elements remain close to the external temperature. 


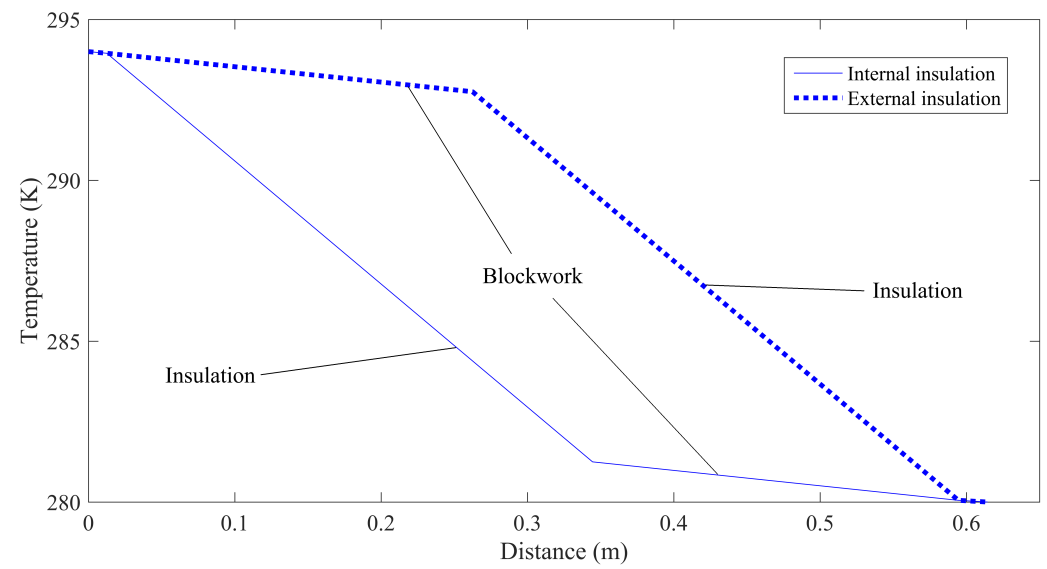

Figure 10: Temperature profile for the steady-state analysis for the two well-insulated walls

With insulation on the outside, the high thermal mass in the interior keeps the temperature during unoccupied hours higher, increasing the overnight heat loss and the overall energy consumption. This additional heat loss will always outweigh the gain made at the start of the next heating period.

\subsection{Evaluation of the TER for cool winter analysis}

These models serve to give insight into the effects of wall type and thermal mass on overall energy use. The assumptions made are general enough that results will be substantially similar for any cool maritime winter climate, for these wall types used for office and domestic buildings. The TER and effective U-values provide a way to quantify the transient performance of various wall types; and high thermal mass walls are shown to be a clear disadvantage under certain conditions.

\subsection{Comparison with Experiment}

\subsubsection{Experimental Background}

In order to verify the TER method, a validation exercise was undertaken using previously published experimental data. The experimental data presented here is taken from a study by Byrne et. al.[51]. The cited study involved a measurement of temperatures and heat fluxes in order to measure the U-value of a house near the north-west coast of Ireland, before and after a retrofit including cavity insulation. As this was an in-situ study, the 
Table 6: Passivhaus retrofit study: TER and $U_{e}$

\begin{tabular}{l|c|c|c}
\hline Wall & $\begin{array}{c}\text { Mean tem- } \\
\text { perature } \\
\text { difference } \\
\text { during } \\
\text { occupied } \\
\text { hours }\end{array}$ & $\begin{array}{c}\text { Transient } \\
\text { energy ratio }\end{array}$ & $\begin{array}{c}\text { Effective } \\
\text { U-value }\end{array}$ \\
& $\mathrm{K}$ & & $\mathrm{W} / \mathrm{m}^{2}$ \\
\hline Theoretical no-mass wall & 13.5 & 1 & 0.15 \\
Solid wall & 10.9 & 2.16 & 3.50 \\
Wall with internal insulation & 12.9 & 3.07 & 0.46 \\
Wall with external insulation & 13.1 & 3.72 & 0.56 \\
\hline
\end{tabular}

measured U-value is the effective U-value by definition: it was calculated by measuring the heat flux and dividing by the measured temperature difference across the wall.

Several authors have identified substantial discrepancies between measured U-values and those predicted by static calculation methods; Byrne et. al. provide a summary of such work to date in their paper. A similar effect is shown in their own work, which finds that cavity insulation added to the house does not bring about the calculated reduction in heat flux through the wall, although it does substantially reduce it.

There are a number of limitations in using the results presented here to analyse the experimental work presented in [51]:

- The exact location and date of the experiments was unknown. Northern Ireland has a sufficiently uniform climate that the use of data for Belfast (perhaps $100 \mathrm{~km}$ away) is reasonable. Byrne et. al. describe the weather conditions during the study as typical for October/November and April/May.

- There was substantial uncertainty in the material properties and construction of the existing wall. Although this data would be needed for a full simulation, the effective U-value of the wall was measured in its pre-retrofit state, allowing a useful comparison between the before and after cases.

- The walls were insulated using pumped cavity insulation, leading to 
uncertainty in the exact thickness and uniformity achieved. Byrne et. al. estimated the amount of insulation added, and the authors of the present study have accepted this value.

- The house in the experiment was unoccupied, but it was monitored for a heat up period of 3 days and a heated period of 4 days. This is an occupied:total time ratio of 0.43 , whereas the TER was calculated assuming 9-5 heating every day (a ratio of 0.33 ). This slightly affects the TER, but given the other uncertainties the additional error introduced is not substantial.

Although an ideal experiment might eliminate these uncertainties, in many ways they are typical of the uncertainties facing a real retrofit project, where original construction details and material properties are subject to significant variability.

\subsubsection{Results}

For this comparison, the TER result from Table 4 is used. The TER for a particular cavity wall in Belfast was found to be 2.65, and for a solid wall it was 2.16 (Table 6 ). A value of 2.65 is assumed here, for the cavity wall in the experimental house.

Byrne et. al. found an R-value for the house in the pre-retrofit case of 0.372 , which corresponds to $U_{e}=2.69 \mathrm{~W} \mathrm{~m}^{-2} \mathrm{~K}^{-1}$ (as $U=\frac{1}{R}$ ). Using the relationship given in Equation 8 with a TER of 2.65 gives a static U-value for this wall of $1.01 \mathrm{~W} \mathrm{~m}^{-2} \mathrm{~K}^{-1}$. This is a reasonable value for an uninsulated cavity wall of this era - see Table 7 .

$$
\mathrm{TER}=\frac{U_{e}}{U}
$$

Taking $U=1.01$ as found above, an estimate of the static and effective U-values can be made for the post-retrofit case. This requires a knowledge of the thickness and properties of the insulation added. Byrne et. al. give a value of $3.125 \mathrm{~m}^{2} \mathrm{~K} / \mathrm{W}$ for the increase in thermal resistance during the retrofit, based on the certified properties of the insulation used. Adding this to the $\mathrm{R}$-value for the uninsulated wall gives a static $\mathrm{U}$-value of $0.243 \mathrm{~W} \mathrm{~m}^{-2} \mathrm{~K}^{-1}$. This latter figure is typical of the target values for new construction or modifications specified in many national standards in Northern Europe.

Applying the TER found for a cavity wall, 2.65, results in a reduced performance for the wall in the post-retrofit case, with $U_{e}=0.64 \mathrm{~W} \mathrm{~m}^{-2} \mathrm{~K}^{-1}$. 
Table 7: Assumed wall construction for the experimental house in [51]

\begin{tabular}{l|c|c}
\hline Wall & $\begin{array}{c}\text { Conductivity[52] } \\
\mathrm{W} \mathrm{m}^{-1} \mathrm{~K}^{-1}\end{array}$ & $\begin{array}{c}\text { Thickness } \\
\mathrm{mm}\end{array}$ \\
\hline Render & 1.5 & 20 \\
Concrete & 1.5 & 250 \\
Internal insulating board & 0.05 & 40 \\
Plaster & 1.5 & 20 \\
\hline Total static U-value & $1.01 \mathrm{Wm}^{-2} \mathrm{~K}^{-1}$ \\
\hline
\end{tabular}

Experimentally, the heat flux and temperature measurements give an $\mathrm{R}$-value of 1.60. This corresponds to a measured $U_{e}$ of $0.62 \mathrm{~W} \mathrm{~m}^{-2} \mathrm{~K}^{-1}$.

The very close agreement between the calculated and measured values is promising. It suggests that thermal mass does indeed play a large role in the failure of retrofits to live up to predicted performance. Other factors, such as moisture ingress, cracks, extra wall ties and unseen thermal bridges will no doubt play a significant role in many structures. Given the assumptions made regarding the construction of the house in the experiment, it is difficult to put a precise figure on the uncertainty associated with the values of $U$ and $U_{e}$; but the results are nevertheless suggestive that this method has real value.

\section{Conclusions and evaluation}

High thermal mass is often presented as a desirable feature of buildings and structures. Indeed, in many cases discussion of thermal mass takes precedence over discussion of insulation performance. Unfortunately, the effects of thermal mass are very poorly quantified in the existing literature. The transient energy ratio provides a way to quantify the effects of thermal mass, distinct from the insulating effect of greater wall thickness and lower conductivity. The experimental application shows that the method can provide useful, quantitatively accurate results much more readily than a full building simulation, and crucially, it provides a degree of insight that more complicated methods do not. It is also robust, and gives meaningful results when applied to an old structure during retrofit. Such a structure would be very difficult to model in a high-fidelity building simulation with any accuracy owing to the substantial lack of knowledge regarding the precise materials and construction details in an old building. In this respect, the TER method 
has significant potential.

In terms of analysis for new-build structures, the results for a hot climate with large diurnal temperature variations and intermittent occupancy show that substantial reductions in energy use are possible, which is in agreement with accepted results regarding thermal mass. However, for cold climates where heating rather than cooling is the predominant concern, this analysis shows that thermal mass can often be a drawback, and the drive towards high thermal mass structures in such regions warrants much further study before it is universally applied. Thermal mass can be considered in conjunction with heating strategies providing higher amounts of preheating/precooling, but unless the energy source is time-dependent or variable-efficiency (such as solar heating) such a strategy will always be sub-optimal. The use of the effective U-value to quantify the dynamic performance of walls is a useful way to quantify the penalty imposed by thermal mass when intermittent occupancy is considered; the scenarios presented here show that static Uvalues alone do not provide an adequate description. As the two heavilyinsulated examples show, the ordering of layers within a wall, is of crucial importance. The same conclusions apply to both new-build construction and retrofit, and for cold climates it will, generally speaking, be preferable to provide insulation on the inside of high thermal mass structural layers, rather than on the outside. More generally, for the equivalent overall conductivity, a design goal in cold climates ought to be a reduction in thermal mass, rather than an increase in it.

This study has looked at the heat flows only, and makes no allowance for the method of heating or cooling. Where other factors are at play (such as, for example, interseasonal heat storage warmed by the sun in summer, and providing heat in winter), then the conclusions may be different. The results presented here do, however, stretch beyond those of the particular occupancy patterns and wall types considered. The authors carried out similar analyses for a range of locations, occupancy patterns and wall types, with broadly similar results; and the method is applicable, in principle, to any type of construction to provide a quantitative analysis of the effects of thermal mass on energy use.

\section{Acknowledgements}

This work was funded by the European Union as a Horizon 2020 project under grant number R6525ARC, and the authors would like to express their 
thanks to the funding bodies and partners for making this possible. 


\section{A. Details of the Finite Element Model}

\section{A.1. Solving the Heat Equation}

The paper presents finite element models constructed in Abaqus CAE 6.12-2; the techniques and methods presented in this paper would work equally well with other programs, or indeed other numerical methods. The model domain comprises a unit square in area, with the thickness for each calculation determined by the particular wall typology. Material thermal properties are as given in the body of this article; surface emissivities are taken as 0.9 for all materials. The authors chose a three dimensional model as they plan to extend the same method to analysis of more detailed wall sections; the heat flow in these analyses was one dimensional, and this was correctly represented by the FE model, with out-of-plane heat fluxes everywhere less than $10^{-10} \mathrm{~W} / \mathrm{m}^{2}$ (the very slight departure from the analytical case being caused by rounding errors, and being much less than that caused by anisotropy in any real wall).

The finite element method is used in this paper to find a solution to the heat equation, with no internal heat generation:

$$
\frac{\partial T}{\partial t}=\alpha \nabla^{2} T
$$

With no heat generation, the energy equation reduces to Equation A2[53]:

$$
\int_{V} \rho \frac{\partial u}{\partial t} \mathrm{~d} V=\int_{S} q \mathrm{~d} S
$$

Combining A1 and A2, the variational form becomes[54]:

$$
\int_{V} \rho \frac{\partial u}{\partial t} \delta T \mathrm{~d} V+\int_{V} \frac{\partial(\delta T)}{\partial r} \cdot k \cdot \frac{\partial T}{\partial r} \mathrm{~d} V=\int_{S} \delta T q \mathrm{~d} S
$$

The discrete weak formulation of Equation A3 is obtained via the Galerkin method. Abaqus implements the backward difference algorithm to generate the discrete time formulation from the continuous time statement in A3, which is solved via the modified Newtonian method[54].

All boundaries not normal to the $x$ axis have $\frac{\partial T}{\partial y}=\frac{\partial T}{\partial z}=0$. The other boundaries (i.e. internal and external faces) have either an insulating boundary represented by a homogeneous Neumann condition, or a convective boundary condition, with the heat transfer coefficient as described. The sink temperature on each face is piecewise linear, with tabular values corresponding to the external weather data or the prescribed internal temperature. 


\section{A.2. Run Time, Mesh Density and Timesteps}

A mesh sensitivity analysis was carried out to check that the mesh size was not going to cause any unwanted artefacts or inaccuracies. A model of an insulated wall between two concrete slabs was modelled using a $40 \mathrm{~mm}$, $20 \mathrm{~mm}$ and $7 \mathrm{~mm}$ spacing. The wall comprised a $120 \mathrm{~mm}$ concrete slab, $120 \mathrm{~mm}$ of insulation, and an $80 \mathrm{~mm}$ facing slab. The three different mesh densities produced almost identical results: Figure A1 shows the temperature profile through the wall at the centre of the model, for each mesh density, and Figure A2 shows sections through the wall, at the same timestep, for each mesh. Both figures show negligible difference between the results at each mesh density. The steady-state results for these meshes were very similar to the temperature profile predicted by a hand calculation. This all suggests that the finite element model, with these mesh densities, is performing adequately.

The computation time for these models was generally quite low, in comparison to many more elaborate finite element simulations. The running time on a computer with $8 \mathrm{~Gb}$ of RAM, using an Intel Xeon E5 processor running at $2.8 \mathrm{GHz}$, was of the order of a few tens of seconds for the week-long simulations for Madrid, and a few minutes for the longer simulations of the wall in Belfast. With these run times, further optimisation of the mesh density

and timestep intervals was not required. Consequently, a $7 \mathrm{~mm}$ mesh was deemed to be adequate.

For the simulations presented in this article, the mean mesh density over the whole domain was around a $7 \mathrm{~mm}$ spacing; a greater density was used in thinner wall sections or those with a high conductivity, where the temperature gradients were steepest. In the case of the lightweight timber wall, which was only $20 \mathrm{~mm}$ thick, the mesh denstiy was increased on a uniform $1 \mathrm{~mm}$ spacing to capture the steeper temperature gradients accurately. 


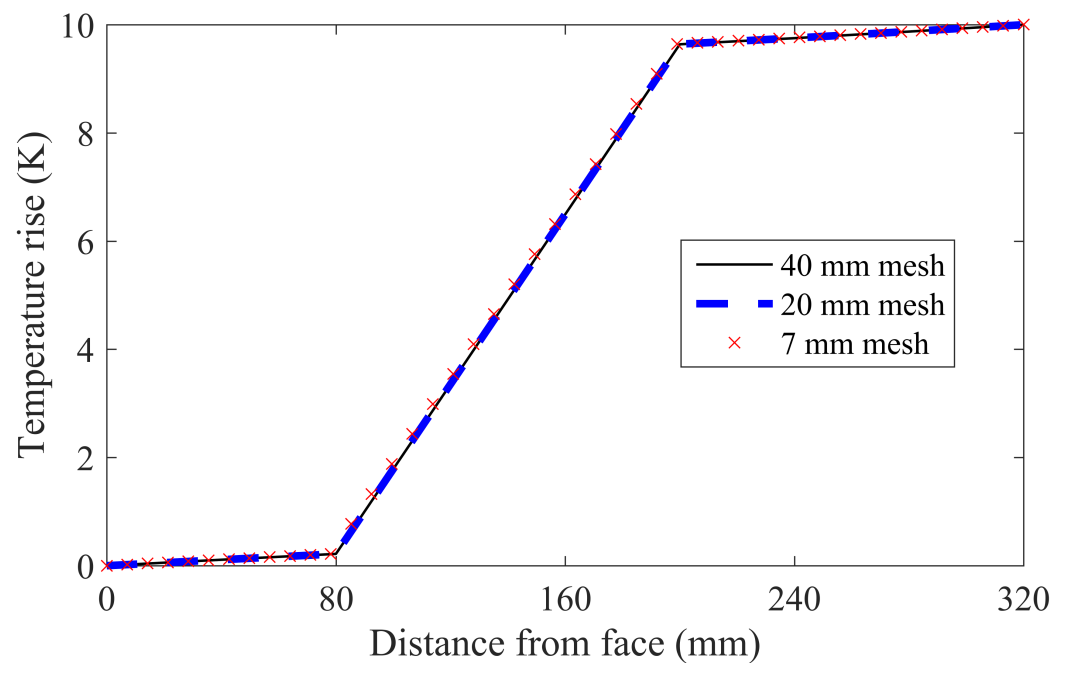

Figure A1: Temperature profile at three mesh spacings
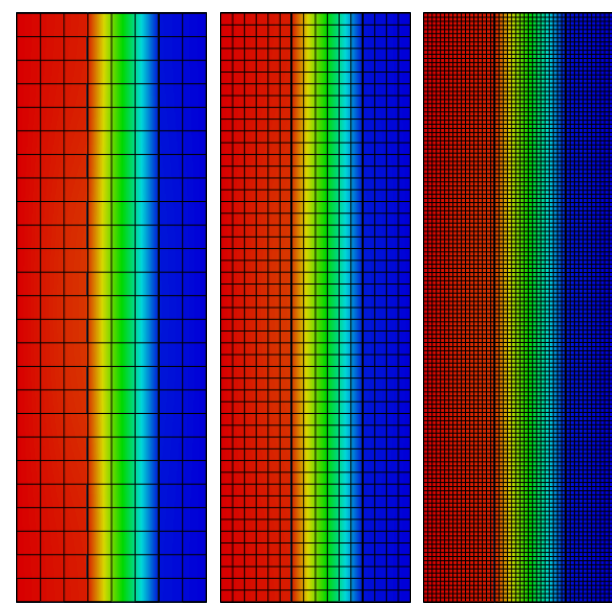

Temperature Rise

든 $10 \mathrm{~K}$

$5 \mathrm{~K}$

$0 \mathrm{~K}$

Figure A2: Section through the trial wall at three different mesh spacings 
[1] L.A. Bellamy and D.W. Mackenzie. Thermal performance of buildings with heavy walls. Technical report, BRANZ, New Zealand, 2001.

[2] Paul Raftery, Edwin Lee, Tom Webster, Tyler Hoyt, and Fred Bauman. Effects of furniture and contents on peak cooling load. Energy and Buildings, 85:445 - 457, 2014.

[3] Hicham Johra and Per Heiselberg. Influence of internal thermal mass on the indoor thermal dynamics and integration of phase change materials in furniture for building energy storage: A review. Renewable and Sustainable Energy Reviews, 69:19 - 32, 2017.

[4] M. A. van Geem, T. A. Holm, and J. P. Ries. Optimal thermal mass and R-Value in concrete. In First International Conference on Concrete Sustainability, 2013.

[5] International Organization for Standardization, Geneva, Switzerland. ISO 13786:2007: Thermal performance of building components - dynamic thermal characteristics - calculation methods.

[6] International Organization for Standardization, Geneva, Switzerland. ISO 13792:2005: Thermal performance of buildings - calculation of internal temperatures of a room in summer without mechanical cooling simplified methods.

[7] Vincenzo Corrado and Simona Paduos. New equivalent parameters for thermal characterization of opaque building envelope components under dynamic conditions. Applied Energy, 163:313-322, Feb. 2016.

[8] Eva Berg-Hallberg. Realistic design outdoor temperatures. Batiment International, Building Research and Practice, 13(5):310-317, 1985.

[9] Department for Communities and Local Government (UK. Building Regulations, Approved Document L: Conservation of Fuel and Power, 2016 .

[10] Department of Energy and Climate Change, now Department for Business, Energy \& Industrial Strategy. The government's standard assessment procedure for energy rating of dwellings, 2012 edition, dated 2013, revised 2014. 
[11] Oliver Kinnane, Derek Sinnott, and William J.N. Turner. Evaluation of passive ventilation provision in domestic housing retrofit. Building and Environment, 106:205 - 218, 2016.

[12] J. Kosny and E. Kossecka. Multi-dimensional heat transfer through complex building envelope assemblies in hourly energy simulation programs. Energy and Buildings, 34(5):445-454, 2002.

[13] Kristen S. Cetin, Lance Manuel, and Atila Novoselac. Effect of technology-enabled time-of-use energy pricing on thermal comfort and energy use in mechanically-conditioned residential buildings in cooling dominated climates. Building and Environment, 96:118-130, FEB 1 2016 .

[14] Katherine Gregory, Behdad Moghtaderi, Heber Sugo, and Adrian Page. Effect of thermal mass on the thermal performance of various australian residential constructions systems. Energy and Buildings, 40(4):459465, 2008.

[15] Niccolò Aste, Adriana Angelotti, and Michela Buzzetti. The influence of the external walls thermal inertia on the energy performance of well insulated buildings. Energy and Buildings, 41(11):1181 - 1187, 2009.

[16] H. Asan. Numerical computation of time lags and decrement factors for different building materials. Building and Environment, 41(5):615$620,2006$.

[17] Elisabeth Kossecka and Jan Kosny. Influence of insulation configuration on heating and cooling loads in a continuously used building. Energy and Buildings, 34(4):321 - 331, 2002.

[18] M.Lj. Bojić and D.L. Loveday. The influence on building thermal behavior of the insulation/masonry distribution in a three-layered construction. Energy and Buildings, 26(2):153 - 157, 1997.

[19] K.W. Childs. Appraisal of the $\mathrm{m}$ factor and the role of building thermal mass in energy conservation. Technical report, Oak Ridge National Laboratory, 1980. 
[20] Jonathan Karlsson, Lars Wadsö, and Mats Öberg. A conceptual model that simulates the influence of thermal inertia in building structures. Energy and Buildings, 60:146 - 151, 2013.

[21] A. Clements. Thermal performance of laminated buildings. Master's thesis, University of Cambridge, 2013.

[22] P.T. Tsilingiris. On the thermal time constant of structural walls. Applied Thermal Engineering, 2004.

[23] Virginia Gori, Valentina Marincioni, Phillip Biddulph, and Clifford A. Elwell. Inferring the thermal resistance and effective thermal mass distribution of a wall from in situ measurements to characterise heat transfer at both the interior and exterior surfaces. Energy and Buildings, 2016.

[24] Peizheng Ma and Lin-Shu Wang. Effective heat capacity of interior planar thermal mass (iptm) subject to periodic heating and cooling. Energy and Buildings, 47:44 - 52, 2012.

[25] Kevin J. Kircher and K. Max Zhang. On the lumped capacitance approximation accuracy in RC network building models. Energy and Buildings, 108:454-462, 2015.

[26] C.P. Underwood. An improved lumped parameter method for building thermal modelling. Energy and Buildings, 79:191 - 201, 2014.

[27] T. van Hooff, B. Blocken, H. J. P. Timmermans, and J. L. M. Hensen. Analysis of the predicted effect of passive climate adaptation measures on energy demand for cooling and heating in a residential building. Energy, 94:811-820, Jan. 2016.

[28] Patrikas Bruzgevičius, Arūnas Burlingis, Vytautas Stankevičius, Darius Pupeikis, Rosita Norvaišienè, and Karolis Banionis. Investigation into thermal capacitance of the building envelope. Journal of Sustainable Architecture and Civil Engineering, 1(2), 2013.

[29] P. Hoes and J.L.M. Hensen. The potential of lightweight low-energy houses with hybrid adaptable thermal storage: Comparing the performance of promising concepts. Energy and Buildings, 110:79 - 93, 2016. 
[30] P. Hoes, M. Trcka, J.L.M. Hensen, and B. Hoekstra Bonnema. Investigating the potential of a novel low-energy house concept with hybrid adaptable thermal storage. Energy Conversion and Management, 52(6):2442 - 2447, 2011. 9th International Conference on Sustainable Energy Technologies (SET 2010).

[31] P. Hoes, M. Trcka, J.L.M. Hensen, and B. Hoekstra Bonnema. Exploring the optimal thermal mass to investigate the potential of a novel low-energy house concept. In Proceedings of the 10th International Conference for Enhanced Building Operations, page 1 to 9. Technische Universiteit Eindhoven, 2010.

[32] Dariusz Heim and Anna Wieprzkowicz. Positioning of an isothermal heat storage layer in a building wall exposed to the external environment. Journal of Building Performance Simulation, 9:1-13, 2016.

[33] P.T. Tsilingiris. Wall heat loss from intermittently conditioned spaces - the dynamic influence of structural and operational parameters. Energy and Buildings, 38(8):1022 - 1031, 2006.

[34] Jorge S. Carlos. The impact of thermal mass on cold and hot climate zones of portugal. Indoor and Built Environment, 2016.

[35] Lin-Shu Wang and Peizheng Ma. The homeostasis solution - mechanical homeostasis in architecturally homeostatic buildings. Applied Energy, 162:183-196, Jan 2016.

[36] Portland Cement Association. http://www.concretethinker.com/solutions/Thermal-Mass.aspx accessed 14-11-2016, 2016.

[37] American National Standards Institute. Energy conservation code, 2009.

[38] C. Luo, B. Moghtaderi, and A. Page. Modelling of wall heat transfer using modified conduction transfer function, finite volume and complex fourier analysis methods. Energy and Buildings, 42(5):605 - 617, 2010.

[39] Bharath K. Karambakkam, Bereket Nigusse, Jeffrey D. Spitler, and C. M. Leonard Professor. A one-dimensional approximation for transient multidimensional conduction heat transfer in building envelopes. In Proceedings of the 7th Symposium on Building Physics in the Nordic 
Countries, pages 340 - 347. The Icelandic Building Research Institute, 2005.

[40] Dervilla Niall. Influence of ground granulated blast furnace slag on the thermal properties of pcm-concrete composite panels. In Advanced Building Skins, Bern, 2016.

[41] J A Clarke, P P Yaneske, and A A Pinney. The harmonisation of thermal properties of building materials, 1990.

[42] International Organization for Standardization, Geneva, Switzerland. ISO 15927-6:2007: Hygrothermal performance of buildings - calculation and presentation of climatic data - part 6: Accumulated temperature differences (degree-days).

[43] The Weather Company. Weather Underground, 2016.

[44] Michael Boxwell. Solar Electricity Handbook - 2016 Edition. Greenstream Publishing, 10th edition, 2016.

[45] A. de Miguel and J. Bilbao. Test reference year generation from meteorological and simulated solar radiation data. Solar Energy, 78(6):695703, 2005.

[46] Agencia Estatal de Meteorología. Climatological data, 2016.

[47] Ray Galvin. Making the 'rebound effect' more useful for performance evaluation of thermal retrofits of existing homes: Defining the 'energy savings deficit' and the 'energy performance gap'. Energy and Buildings, $69: 515-524,2014$.

[48] D. P. Bloomfield and D. J. Fisk. The optimisation of intermittent heating. Building and Environment, 1977.

[49] Building Research Establishment. Solid wall heat losses and the potential for energy saving, 2014.

[50] Sustainable Energy Ireland. Retretrofit passive homes, 2009.

[51] Aimee Byrne, Gerard Byrne, Anna Davies, and Anthony James Robinson. Transient and quasi-steady thermal behaviour of a building envelope due to retrofitted cavity wall and ceiling insulation. Energy and Buildings, 61:356 - 365, 2013. 
[52] A.J. Robinson, F.J. Lesage, A. Reilly, G. McGranaghan, G. Byrne, R. O'Hegarty, and O. Kinnane. A new transient method for determining thermal properties of wall sections. Energy and Buildings, 2017.

[53] A. E. Green and P. M. Naghdi. A general theory of an elastic-plastic continuum. Archives of Rational Mechanics and Analysis, 17, 1965.

[54] Hibbitt, Karlsson, and Sorensen. Abaqus Theory Manual. 6.10 edition, 1984 (2012). 